\title{
Pilot study: a randomised, double blind, placebo controlled trial of pancrealipase for the treatment of postprandial irritable bowel syndrome-diarrhoea
}

\author{
Mary E Money, ${ }^{1,2}$ Jaroslaw Walkowiak, ${ }^{3}$ Chris Virgilio, ${ }^{1,4}$ Nicholas J Talley,
}

\author{
'Washington County Health \\ Systems, Hagerstown, Maryland, \\ USA \\ ${ }^{2}$ Department of Internal \\ Medicine, University of \\ Maryland, Baltimore, Maryland, \\ USA \\ ${ }^{3}$ Department of Gastroenterology \\ and Metabolism, Poznań \\ University of Medical Sciences, \\ Poznań, Poland \\ ${ }^{4}$ Bernard I Dunn School \\ of Pharmacy, Shenandoah \\ University, Winchester, Virginia, \\ USA \\ ${ }^{5}$ Department of Medicine, Mayo \\ Clinic, Mayo Clinic College of \\ Medicine, Jacksonville, Florida, \\ USA \\ ${ }^{6}$ Faculty of Health, Bowman \\ Building, University of \\ Newcastle, Callaghan, NSW, \\ Australia
}

\section{Correspondence to}

Dr M E Money, Washington

County Health Systems, 354 Mill

Street, Hagerstown, MD 21740,

USA;

MEWaldman@aol.com

Accepted 24 September 2010

Published Online First

3 November 2010
Objective To evaluate the efficacy of pancrealipase (PEZ) compared with placebo in the reduction of postprandial irritable bowel syndrome-diarrhoea (IBS-D).

Design An intention to treat, double blind, randomised, crossover trial comparing PEZ to placebo for reduction of postprandial IBS-D. Patients had to recognise at least two different triggering foods, be willing to consume six baseline 'trigger meals' and again blinded with PEZ and placebo. Patients then chose which drug they preferred for another 25 meals. Setting Outpatient internal medicine practice clinic.

Patients 255 patients were screened; 83 met the criteria, including 5 years of symptoms, recognised 'food triggers', no other identifiable cause for the symptoms, either a normal colonoscopy or barium enema while symptomatic and able to discontinue all anticholinergic medications. 69 patients were enrolled, 20 withdrew before randomisation, leaving 49 patients: 14 men, 35 women, mean age 52 years (SD 15.3). Over 60\% had experienced symptoms for 11-30 years and $16 \%$ for more than 40 years. Interventions After completing six baseline meals, patients were randomised in blocks of four to receive either identical PEZ or a placebo for another six meals, and after a washout period of time received the alternative drug.

Main outcome measures The primary analysis was number of patients who chose PEZ over placebo for the extended use. Results Overall, 30/49 (61\%) would have chosen PEZ ( $p=0.078)$, with first drug preference for PEZ at 0.002. Among the PEZ subgroup, PEZ use compared with placebo, demonstrated improvement in all symptoms $(p \leq 0.001)$ for cramping, bloating, borborygami, urge to defecate, global pain and decrease stooling with increase in stool firmness.

\section{What is already known about this subject? \\ - The irritable bowel syndrome affects close to $15 \%$ of the population and approximately one-third of these individuals have the diarrhoea condition. \\ - The diagnosis is made on the Rome III symptom criteria which have not been validated to exclude organic disease. \\ - The Rome III criteria do not include what precedes the diarrhoea as being important although $50-75 \%$ of individuals recognise that the diarrhoea occurs after eating. \\ - Treatment recommendations for the irritable bowel syndrome-diarrhoea condition do not routinely include pancrelipase.}

\section{What are the new findings?}

- A subgroup of patients with irritable bowel syndrome-diarrhoea responded with a reduction of their postmeal symptoms by the ingestion of pancrelipase before eating.

\section{How might they impact on clinical} practice in the foreseeable future?

- This study may increase the recognition that these patients may have a form of maldigestion which can be improved by the supplementation of pancrelipase before consuming a meal or known 'trigger'.

- Further research may be stimulated by this pilot study.

Conclusions PEZ was found in a small group of patients to reduce postprandial IBS-D symptoms and deserves further evaluation.

\section{Introduction}

At the current time, a large number of individuals are experiencing major gastrointestinal complaints after consuming certain foods, liquids, spices, etc. If diarrhoea 
is present, complaints are typically diagnosed as either functional diarrhoea (if without pain) or the 'irritable bowel syndrome-diarrhoea' (IBS-D), if pain is present with the episode. ${ }^{1-5}$ IBS is a condition affecting an estimated $10-15 \%$ of the US population. ${ }^{67}$ Although not included in the widely accepted Rome criteria for IBS, ${ }^{78}$ theories for why the symptoms occur after eating have included the following: food intolerance, food allergies or hypersensitivity, an alteration of bowel bacteria or psychosocial factors. ${ }^{9-11}$

A maldigestion or malabsorption problem is not usually considered if the food product is not related to lactose. However, a recent study conducted by Shepherd suggested that fructose malabsorption contributed to some of these complaints. ${ }^{12} \mathrm{~A}$ low $\alpha$-glucosidase activity has been recognised as the cause of chronic osmotic diarrhoea in $21 \%$ of children diagnosed with recurrent abdominal pain associated with diarrhoea, ${ }^{12 a}$ and has also been recognised in adults. ${ }^{13-15}$ The diagnosis of a disaccharidase deficiency which clinically causes diarrhoea after eating is only made after the objective finding of a deficiency in the concentration of the enzymes in the brush border of the small intestine or the presence of a high osmotic gap in stool water that has a $\mathrm{pH}$ $<5$. These tests are not usually performed on patients who meet the criteria for IBS-D.

Mainstream treatment recommendations for IBS-D, other than dietary modifications, have predominantly been antidiarrhoeal agents such as loperamide and diphenoxylate, tricyclic antidepressants or alosetron, a $5 \mathrm{HT}_{3}$ receptor antagonist. ${ }^{76-18}$ Other possible therapies have included clonidine, ${ }^{19}$ cholestyramine, ${ }^{18}$ Chinese herbal therapy, ${ }^{20} 21$ cromolyn $^{22}{ }^{23}$ and psychotherapy ${ }^{2425}$ Antispasmodic agents such as hyoscyamine and dicyclomine are often prescribed but have not been established to be beneficial and may lose any possible benefit over time. ${ }^{7}$ Pancrealipase (PEZ) has been shown to reduce bile acid malabsorption in patients with cystic fibrosis, ${ }^{26-28}$ chronic pancreatitis, ${ }^{29}$ fat malabsorption due to $\mathrm{HIV}^{30}$ and improve digestion in normal patients consuming a fatty meal. ${ }^{31}$ PEZ has recently been reported as being effective for the postprandial IBS-D condition ${ }^{32}$ and among patients identified with pancreatic insufficiency who also have IBS. ${ }^{33}$ $\alpha$-Amylase, a major component of PEZ, has been shown to augment disaccharidase activity. ${ }^{34} 35$

We hypothesised that some symptoms of IBS are due to maldigestion and/or malabsorption of certain foods. We therefore aimed to test the effectiveness of PEZ compared with placebo in the reduction of the symptoms in patients who have IBS-D after eating known triggering agents.

\section{Methods}

\section{Patients}

Patients were recruited by referral from local physicians and advertisements. Strict eligibility and exclusion criteria were used to establish the patient group including:
18 years or older; at least 5 years of only IBS-D symptoms before age 50 years, at least 12 times annually which had to occur within $3 \mathrm{~h}$ of eating at least two different triggering foods (specific for each patient); and onset before a cholecystectomy. Intolerance only to milk products was not acceptable. Patients were not eligible if they had unexplained weight loss, felt symptoms were due to medication or had been diagnosed with other gastrointestinal disorders which might explain the symptoms. A normal colonoscopy or a barium enema was required to have been completed while having postprandial symptoms. Discontinuation of gastrointestinal anticholinergic agents prior to enrolment was required and was not permitted to be restarted. Antidepressant use was allowed and any new treatments, drug therapies or dosage changes were recorded. Antidiarrhoeal drugs were permitted only after postprandial symptoms started and not before a meal. In total, 49 patients were randomised into the study (see results section below).

All patients entered into the study met the Rome II criteria for IBS: 12 consecutive or non-consecutive weeks or more in the past 12 months of abdominal discomfort or pain with two of the three features of (1) relief with defecation, (2) onset associated with a change in stool frequency and/or (3) onset associated with a change in the form (appearance) of the stool. ${ }^{243637}$

In this study, patients were restricted to having only postprandial IBS-D.

\section{Study design}

An original rigorous study design was created in an attempt to demonstrate PEZ effectiveness over placebo when taken by IBS-D patients before consuming a triggering agent. This study followed a randomised, double blind, placebo controlled, crossover design with patients serving as their own controls. It was felt that a parallel group study design would require more enrollees (see power calculation below). The study was not designed to evaluate for bacterial overgrowth or the presence of malabsorption due to limited funding.

Each patient was required to record the severity of specific postprandial symptoms that occurred after each trigger meal: cramping, bloating, borborygami, nausea, intensity to have a bowel movement, other symptoms of sweating/chills and global pain from 0 to 10. Time of onset, duration of the episode along with stool frequency and consistency were also recorded on a specially designed meal diarrhoea form. Stool consistency was scored in a graduated fashion from normal (2 points) to watery diarrhoea (10 points) (table 1).

The meal list for patients was as follows: one nontrigger meal with a food not recognised to precipitate IBS symptoms; six baseline trigger meals with patient specific known trigger foods; 4-12 trigger meals with drug 1 (blinded: PEZ or identical placebo); another 4-12 trigger meals with drug 2 (blinded: PEZ or 
Table 1 Subjective and objective symptoms scoring for each meal

\begin{tabular}{|c|c|c|}
\hline Symptoms & \multicolumn{2}{|c|}{ Subjective point score } \\
\hline Cramping & \multicolumn{2}{|l|}{$0-10$} \\
\hline Bloating & \multicolumn{2}{|l|}{$0-10$} \\
\hline Borborygami & \multicolumn{2}{|l|}{$0-10$} \\
\hline Nausea & \multicolumn{2}{|l|}{$0-10$} \\
\hline Urge to have a bowel movement & \multicolumn{2}{|l|}{$0-10$} \\
\hline Sweating, chills & \multicolumn{2}{|l|}{$0-10$} \\
\hline Global abdominal pain & \multicolumn{2}{|l|}{$0-10$} \\
\hline No of bowel movements & \multicolumn{2}{|c|}{1 point each bowel movement } \\
\hline Consistency of each stool & \multicolumn{2}{|c|}{ Subjective point score } \\
\hline Normal & \multicolumn{2}{|c|}{2} \\
\hline Soft & \multicolumn{2}{|l|}{4} \\
\hline Mushy, not formed & \multicolumn{2}{|l|}{6} \\
\hline Loose, no water & \multicolumn{2}{|l|}{8} \\
\hline Watery diarrhoea & \multicolumn{2}{|l|}{10} \\
\hline \multicolumn{3}{|l|}{ Onset and duration of symptoms } \\
\hline Time period & Onset points & Duration points \\
\hline 0-30 min & 10 & 2 \\
\hline $31-60$ & 8 & 4 \\
\hline $61-90$ & 6 & 6 \\
\hline $91-120$ & 4 & 8 \\
\hline$>121$ & 2 & 10 \\
\hline
\end{tabular}

identical placebo); and 25-50 meals using their preference (drug 1 or 2 for all meals).

Each patient was permitted to return to their prior treatment or take PEZ after they completed the study. An open label follow-up was conducted 3 months after the study ended. An IBS-Specific Quality of Life (QOL) Health Questionnaire (IBS-QOL), used with permission from Patrick et al, ${ }^{38}$ was completed by each patient at enrolment, completion and 3 months later during the open label follow-up.

\section{Randomisation and concealed allocation}

Only after completion of six baseline trigger meals was each participant enrolled by the study investigator and was randomised according to a computer generated blocked randomisation list using a block size of four to receive as either the first or second drug: PEZ (Viokase: lipase 8000; amylase 30000 ; and protease 30000 ; Axcan Pharma, Quebec, Canada) or placebo capsule (Cebocaps Blue, size 1 from Forest Pharmaceuticals (New York City, New York, USA) containing inert sucrose, starch, acacia, talc, gelatin and artificial colour). Randomisation of patients and concealed allocation were assured by the trial pharmacist who prepared the drug vials which were numbered sequentially.

\section{Blinding and dosing}

Both drugs were placed inside a second dark coloured space capsule, size 0 . Therefore, both drugs were identical by weight and size with no perceivable taste difference. Patients were given 12 capsules for each drug period and were instructed not to open them. Patients were permitted to titrate the dose from 1 to 3 capsules before each meal, and therefore could potentially consume up to 12 meals prior to receiving the next drug if one capsule was effective. This dosage was determined based on the clinical experience of the investigators of effective dosage of PEZ among IBS-D patients currently taking PEZ. After the first drug was used for at least four meals, patients received the alternate drug. A minimum 1 week washout period between drugs was required. Patients were instructed and encouraged to try to consume the same trigger meals for each drug but were not excluded from the study if they failed to meet this requirement. Once both drugs were tried, the patients then chose which of the two drugs (still blinded) they wanted to use for a prolonged period of up to 50 trigger meals (their choice of meals). There was no time pressure for completion of the meals at any phase of the study. Patients were also permitted to use antidiarrhoeal agents as needed for breakthrough diarrhoea.

\section{Follow-up period}

Follow-up by study personnel occurred at completion of the baseline meals, after each drug use, at meal 25 of extended use and after consumption of meal 50. At every visit, each participant was interviewed for protocol adherence, including their attempt at duplication of baseline meals for drug 1 and drug 2, side effects and changes in other medical conditions or medications. Patients and investigators were unaware of the drug sequences or choice of drug for the final use until the entire trial had been concluded. Each patient, on study completion, could contact the trial pharmacist who 
was permitted to disclose to the patient his/her final choice. Therefore, patients could obtain a prescription for PEZ before the conclusion of the trial from their personal physician, if desired. A 3 month follow-up was also done after completion of the study.

The Washington County Hospital Institutional Review Board approved the study and each participant gave written informed consent. Patients could withdraw from the study at any time or be removed for study protocol violations. The trial was approved by the Washington County Hospital Institutional Review Board on 18 January 2002. Enrolment was completed with 49 patients. The study concluded on 4 November 2003.

\section{Statistical analysis}

The primary analysis was the effectiveness of PEZ compared with placebo in reduction of postprandial symptoms among the number of individuals who chose the enzymes as the effective agent for the prolonged use period. A one way $\chi^{2}$ test was used for final analysis of the number of individuals who chose placebo versus PEZ as the effective drug (primary end point) by intention to treat analysis. Independent sample $t$ tests and two way $\chi^{2}$ tests were used to determine any difference among subgroups for age, sex, number of years for IBS-D, positive family history of a similar problem, length of time for completion of the study, frequency of episodes and comparison of effectiveness of their choice of agents. One way $\chi^{2}$ tests were also used to subanalyse both final groups (selected PEZ or placebo) for determining the effectiveness of the drugs compared with baseline average meal scores, enzyme meals, placebo meals and second use of the "choice drug'. Average meal scores for each person were calculated by adding all of the symptom scores for all meals in that section and then dividing by 6 (the total number of meals).

Patient scores were not used if they consumed fewer than six meals in each section for comparison. Individual symptom scores for bloating, nausea, borborygami, cramping, urge for defecation, sweating/ chills and number of bowel movements were individually analysed by one way $\chi^{2}$ tests for the enzyme subgroup comparing enzyme therapy with placebo.

The $t$ test was used for analysis of the QOL measurements before and at the conclusion of the study for this subgroup, and for those patients who were on enzymes at the 3 month follow-up. All p values calculated were two tailed; the $\alpha$ level of significance was set at 0.05 .

\section{Power calculation}

Based on an estimated mean total symptom score of 100 in the placebo group with an SD of 50, it was estimated that approximately 35 patients would be needed to provide $80 \%$ power to detect a $50 \%$ change in symptoms between the drug treatments (PEZ and placebo).

\section{Results}

Participants

A total of 255 patients were screened for the study and 83 met the IBS-D criteria (ineligible patients included those who did not meet the Rome II criteria; had not had a colonoscopy or barium enema; had constipation IBS; did not know their specific triggering foods; and had previously been diagnosed with a medical condition causing the diarrhoea, such as inflammatory bowel disease). Of the 83 eligible patients, 69 were enrolled, but after reviewing the study requirements, 20 withdrew before being randomised. Thus 49 patients were randomised into the study (figure 1).

Patient characteristics were as follows: 14 men, 35 women, mean age 52 years (SD 15.3); 74\% had symptom onset before the age of 30 years; over $60 \%$ had experienced symptoms for 11-30 years; and $16 \%$ had experienced them for more than 40 years. Thirteen patients identified anxiety or depression as a current comorbid condition, and eight were using an antidepressant (paroxetine $(n=3)$, fluoxetine $(n=1)$, sertraline $(n=1)$, desipramine $(n=1)$, venlafaxine $(n=1)$ and amitriptyline $(n=1))$. Two patients were using lorazepam or alprazolam. Eight of the patients had onset of IBS symptoms at least 5 years prior to a cholecystectomy. Prior medications used by patients included: loperamide $(\mathrm{n}=30)$, fibre supplement $(n=22)$, antidepressants $(n=9)$ and anticholinergics $(n=15)$. Prior negative studies included colonoscopy $(n=42)$, barium enema $(n=26)$, upper gastrointestinal examination with small bowel follow through $(n=8)$, oesophagogastroduodenoscopy $(n=10)$ and pancreatic function studies $(n=4)$.

Although not a requirement for participation, 30 patients participated in additional testing for evaluation of pancreatic insufficiency and presence of coeliac disease. Testing for malabsorption, serum IgA levels and antibodies to coeliac disease was completed by one of the authors (JW at the Poznan University of Medical Sciences, Poznań, Poland). All participants had normal endomysium and tissue transglutaminase antigens values for coeliac disease ${ }^{39}{ }^{40} ; 47$ serum lipase measurements were evaluated and only three were less than $10 \%$ above normal (10-60 U/1). ${ }^{41}$ There were 29 measurements for IgA g/l; only two were slightly elevated and none was low (normal $0.7-4.0 \mathrm{~g} / \mathrm{l}$ ). Of the 60 stool specimens tested for faecal elastase 1 , only four registered values less than $200 \mu \mathrm{g} / \mathrm{g}$ faeces, the lowest being $112 \mu \mathrm{g} / \mathrm{g}$. ${ }^{42}$ Three of the four patients who had abnormally low faecal elastase selected the placebo as the 'effective agent'.

Each participant identified an average of 12 triggering foods, ranging from 2 to 23. Common food/ spice triggers included: spicy seasoning (78\%), lettuce (particularly iceberg) (71\%), Italian food (69\%), milk based products (69\%), cabbage (67\%), Chinese food (61\%), fried food (59\%), barbecue spices (49\%), 


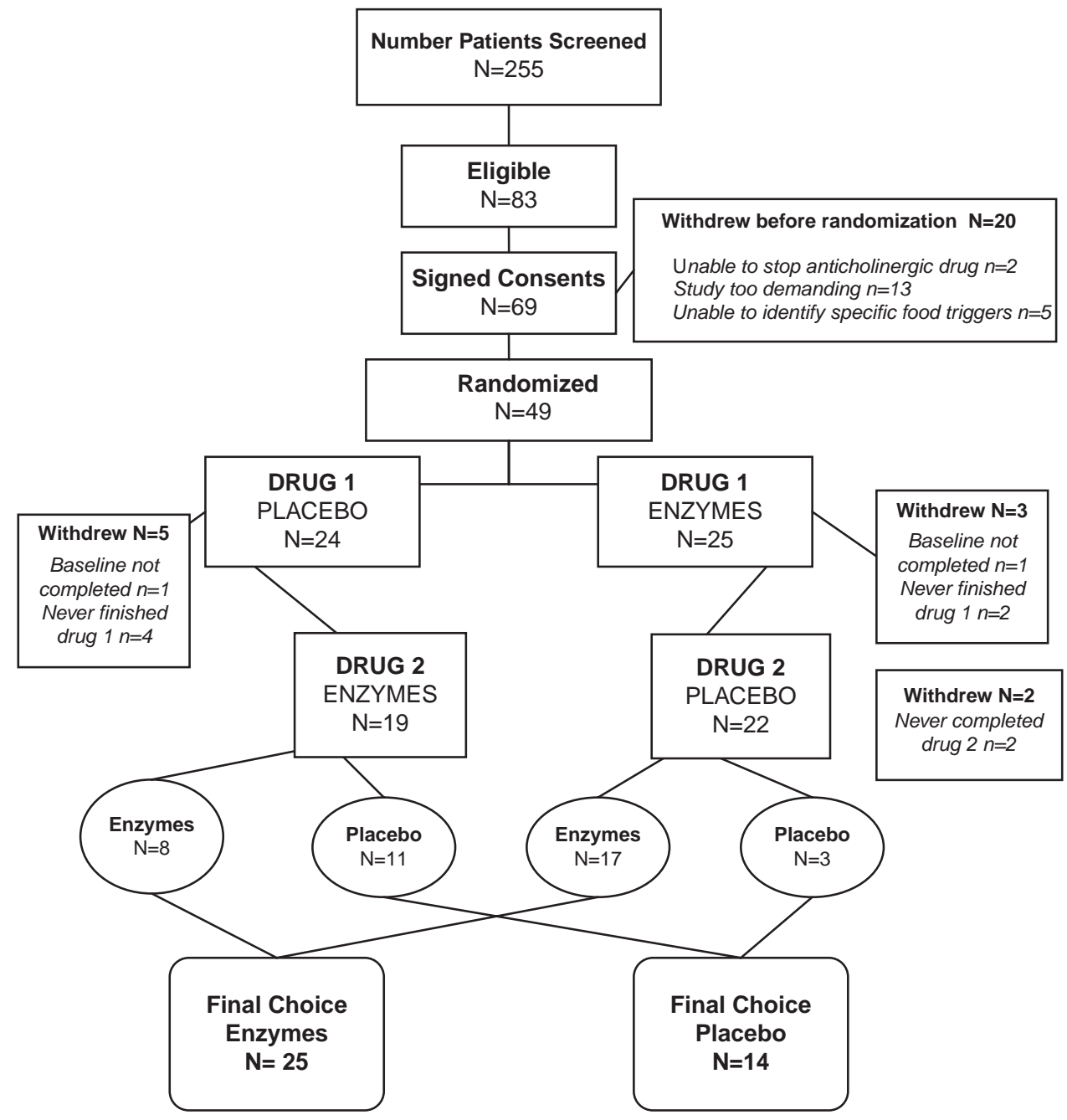

Figure 1 Consort diagram outlining the study design.

hot peppers $(46 \%)$, green peppers $(41 \%)$, tomatoes $(45 \%)$, onions $(43 \%)$, apple $(37 \%)$, eggs $(35 \%)$, orange juice $(31 \%)$, soy sauce $(31 \%)$, beef/pork $(29 \%)$, garlic (24\%), coffee/tea (20\%) and chocolate (14\%). Eighty-eight per cent had symptoms after eating out in a restaurant.

Thirty-two (69\%) of the patients reported another family member with the same problem: father $(n=28)$, mother $(n=24)$, sister $(n=20)$, daughter $(n=4)$, brothers $(n=3)$ and sons $(n=3)$.

\section{Choice of effective agent}

Of the 39 patients who completed the study by using each drug for at least four trigger meals, 25 (64\%) chose PEZ over placebo as the effective agent. Based on the intention to treat analysis by including those individuals who dropped out of the study as failures, 30/49 (61\%) would have chosen enzymes while 19/49 (39\%) would have selected the placebo $(\mathrm{p}=0.078)$. Notably, the $\chi^{2}$ test for selection based on first drug administered was statistically significant with the first drug preference if PEZ were received first $(p=0.002)$ but was not significant if the individual received placebo first $(\mathrm{p}=0.49)$.
Both the placebo subgroup and the enzymes subgroup were analysed for age, gender, family history of similar problems, duration and frequency of IBS-D episodes, and time that it took to complete the study. There was no statistically significant difference in any of the above parameters between the subgroups to reflect their final choice. Loperamide use in both groups was not statistically significant and use decreased by at least $50 \%$ among patients in each group.

\section{Placebo choice and patient withdrawal}

Fourteen patients chose placebo over enzymes, 11 of whom had placebo as their first drug. Effectiveness of the placebo capsule was comparable to PEZ among those who chose the placebo.

Ten patients withdrew from the study. Two never completed the initial six baseline trigger meals and another six patients never completed the first drug meals: four taking placebo, two taking PEZ. Another two patients withdrew after trying the second drug, which was placebo in each case. Thus a total of six out of eight patients withdrew during a placebo drug phase. 
Table 2 Statistical analysis of enzymes compared with placebo for reduction of irritable bowel syndrome-diarrhoea symptoms in enzyme subgroup

\begin{tabular}{lcclcc}
\hline $\begin{array}{l}\text { Symptom } \\
\text { (0-10 severe) }\end{array}$ & Mean with placebo & $\begin{array}{l}\text { Mean with PEZ } \\
\text { as No 1 drug }\end{array}$ & $\begin{array}{l}\text { p Value } \\
\text { (PEZ as No 1 drug) }\end{array}$ & $\begin{array}{l}\text { Mean with PEZ } \\
\text { as choice }\end{array}$ & $\begin{array}{l}\text { p Value } \\
\text { (PEZ as choice) }\end{array}$ \\
\hline Cramping & $3.50 \pm 2.73$ & $1.42 \pm 1.88$ & 0.006 & $1.09 \pm 1.69$ & 0.001 \\
Bloating & $2.72 \pm 1.90$ & $1.31 \pm 1.56$ & 0.009 & $0.90 \pm 1.30$ & 0.000 \\
Borborygami & $3.25 \pm 2.07$ & $1.90 \pm 1.95$ & 0.006 & $1.37 \pm 1.62$ & 0.001 \\
Nausea & $0.53 \pm 0.92$ & $0.26 \pm 0.53$ & 0.057 & $0.21 \pm 0.53$ & 0.034 \\
Urgency & $4.63 \pm 2.67$ & $2.14 \pm 2.00$ & 0.002 & $1.79 \pm 1.93$ & 0.000 \\
No of stools & $1.89 \pm 1.03$ & $0.79 \pm 0.91$ & 0.000 & $0.68 \pm 0.88$ & 0.000 \\
Duration attack (min) & $98.94 \pm 92.76$ & $88.54 \pm 181.81$ & 0.898 & $53.47 \pm 86.45$ & 0.072 \\
Sweating & $0.72 \pm 1.18$ & $0.34 \pm 0.63$ & 0.181 & $0.28 \pm 0.60$ & 0.106 \\
Stool consistency & $12.00 \pm 7.12$ & $4.19 \pm 5.24$ & 0.000 & $3.55 \pm 5.50$ & 0.000 \\
Abdominal pain & $3.64 \pm 2.70$ & $1.45 \pm 1.83$ & 0.003 & $1.14 \pm 1.88$ & 0.000 \\
\hline
\end{tabular}

PEZ, pancrealipase.

Table 3 Quality of life (QOL) comparison between baseline and completion of trial for pancreatic enzyme subgroup

\begin{tabular}{|c|c|c|c|c|c|}
\hline \multirow[b]{2}{*}{ QOL parameter } & \multicolumn{2}{|l|}{ Baseline } & \multicolumn{3}{|c|}{ Completion of trial } \\
\hline & Mean & $\mathrm{N}$ & Mean & $t$ & $\mathrm{p}$ Value \\
\hline Dysphoria & $45.74 \pm 28.08$ & 22 & $75.71 \pm 21.97$ & -5.04 & 0.000 \\
\hline Interference w/activity & $37.42 \pm 18.02$ & 21 & $68.54 \pm 21.36$ & -6.14 & 0.000 \\
\hline Body image & $70.07 \pm 23.35$ & 19 & $86.84 \pm 15.44$ & -3.27 & 0.004 \\
\hline Health worry & $64.68 \pm 16.65$ & 21 & $82.94 \pm 13.30$ & -4.55 & 0.000 \\
\hline Food avoidance & $20.83 \pm 20.21$ & 22 & $56.06 \pm 27.96$ & -5.55 & 0.000 \\
\hline Social reaction & $54.89 \pm 19.49$ & 23 & $76.36 \pm 21.81$ & -4.87 & 0.000 \\
\hline Sexual & $73.21 \pm 33.14$ & 21 & $85.12 \pm 26.70$ & -2.25 & 0.036 \\
\hline Relationships & $56.67 \pm 23.51$ & 20 & $77.50 \pm 19.70$ & -5.35 & 0.000 \\
\hline Overall score & $46.11 \pm 15.35$ & 14 & $77.10 \pm 15.82$ & -5.49 & 0.000 \\
\hline
\end{tabular}

\section{Subanalysis of enzyme subgroup}

Twenty-five of the 39 patients who finished the study (64\%) chose PEZ over placebo as the effective agent. Seventeen had the enzymes as the first drug and eight were given it as the second drug. Among the enzyme subgroup, PEZ resulted in a mean $60.3 \%$ reduction of IBS-D symptoms from baseline meal scores compared with a $34 \%$ change with placebo, which was statistically significant $(p<0.001)$. Individual symptom comparison between enzymes and placebo for this subgroup are shown in table 2 .

Improvement in symptoms $(\mathrm{p} \leq 0.001)$ was identified for cramping, bloating, borborygami, urge to defecate and pain when enzymes were used in comparison with placebo. Likewise, the decrease in the number of stools and increase in stool firmness were statistically significant between placebo and second use of enzymes $(\mathrm{p}<0.001)$.

\section{Compliance with trigger meal consumption and severity of IBS symptoms}

Average scores of the six baseline trigger meals among all participants ranged from 35 to 127 points. These scores did not follow a normal distribution pattern, reflecting the wide range of symptoms. Twenty-seven of the 39 patients who completed the study (69\%) followed the study protocol and consumed identical trigger meals for baseline, drug 1 and drug 2 more than $75 \%$ of the time. There was no difference in meal compliance between the final choice subgroups: PEZ 17/25 (68\%), placebo 10/14 (71\%).

\section{QOL at baseline and completion of study}

Table 3 shows a significant improvement in IBS-QOL scores $(p=0.000-0.036)$ from baseline to completion of the study for the enzyme subgroup participants. A statistical comparison of IBS-QOL scores among patients choosing placebo versus enzymes was not possible due to the small sample size of the placebo subgroup.

\section{Safety and side effects}

There were no serious adverse events during the trial. The only side effect was increased flatus $(n=2$ placebo; $n=1$ PEZ) and mild constipation $(n=1$ placebo; $n=2$ PEZ). One patient complained of increased abdominal pain and insomnia while using the placebo preparation.

\section{Open label 3 month follow-up}

Patients were contacted 3 months after the conclusion of the trial. We located 46 (94\%) patients and 
Table 4 Quality of life (QOL) comparison between baseline and 3 month follow-up of trial for patients using pancreatic enzymes open label after trial completion

\begin{tabular}{|c|c|c|c|c|c|}
\hline \multirow[b]{2}{*}{ QOL parameter } & \multicolumn{2}{|l|}{ Baseline } & \multicolumn{3}{|c|}{3 month follow-up after trial conclusion } \\
\hline & Mean & $\mathrm{N}$ & Mean & $t$ & p Value \\
\hline Dysphoria & $50.60 \pm 26.81$ & 31 & $89.42 \pm 10.35$ & -9.00 & 0.000 \\
\hline Interference w/activity & $44.95 \pm 21.96$ & 29 & $82.27 \pm 15.67$ & -9.32 & 0.000 \\
\hline Body image & $66.59 \pm 26.37$ & 29 & $90.73 \pm 10.51$ & -5.64 & 0.000 \\
\hline Health worry & $64.44 \pm 19.57$ & 30 & $87.50 \pm 12.52$ & -5.99 & 0.000 \\
\hline Food avoidance & $23.61 \pm 21.56$ & 30 & $72.78 \pm 21.43$ & -9.91 & 0.000 \\
\hline Social reaction & $58.27 \pm 21.85$ & 31 & $85.89 \pm 11.96$ & -7.98 & 0.000 \\
\hline Sexual & $73.28 \pm 32.86$ & 29 & $93.53 \pm 10.89$ & -3.76 & 0.000 \\
\hline Relationships & $62.93 \pm 26.97$ & 29 & $92.24 \pm 11.77$ & -7.21 & 0.000 \\
\hline Overall score & $52.65 \pm 18.87$ & 25 & $86.35 \pm 9.38$ & -9.63 & 0.000 \\
\hline
\end{tabular}

31 were now using the enzymes for their postprandial symptoms (six of whom had previously picked placebo and three who had withdrawn from the study). These 31 patients had been using PEZ for an average of 6 months by the time of follow-up. Each of the 31 current users completed a global symptom severity scale of 0 (no problems) to 10 (severe problems) for their current postprandial symptoms compared with before taking the enzymes. These 31 patients scored their baseline severity as 8.6 on the scale of $0-10$, but after using the enzymes they reported a severity of only 2.2. This difference was statistically significant $(\mathrm{p}<0.001)$.

In addition, these patients were asked to complete the formal IBS-QOL survey again. Their responses compared with the baseline QOL continued to show improvement beyond that recorded at the conclusion of the study (table 4).

\section{Discussion}

The majority of patients who suffer from postprandial diarrhoea and have pain are considered to have IBS-D by the process of exclusion after meeting the Rome criteria. However, Hammer and Talley proposed that the validity of the Rome criteria in discriminating IBS from organic disease has not actually occurred..$^{43} \mathrm{~A}$ recent review of 25 diagnostic studies of IBS by Jellema et al also concluded that the symptom based criteria cannot exclude organic disease. ${ }^{44}$ Among patients with symptoms suggestive of IBS-D or functional diarrhoea, the Mayo Clinic studies showed $\sim 45 \%$ had evidence of accelerated colonic transit. ${ }^{45}{ }^{46}$ The cause of the accelerated colonic transit was assumed to be related to abnormal motility; however, the latter may conceivably result from nutrient malabsorption or bile acid malabsorption. In fact, Camilleri et al summarised several potential primary factors that may induce the symptom phenotype of IBS-D or functional diarrhoea, in which transit may be aggravated postprandially, ${ }^{47}$ and in many patients symptoms may be worse after meals, as in nutrient malabsorption, gluten intolerance and bile acid malabsorption. ${ }^{48}$ Consequently, treatment options have been limited since the underlying aetiology has not been established and most patients resort to using antimotility agents by default.

This study was spearheaded by the observation that the majority of patients with postprandial IBS-D in a large internal medicine practice reported a major improvement in symptoms when prescribed PEZ to use before meals (MEM, personal communication). This observation led to the development of the novel pilot trial presented in this report.

The study protocol attempted to reproduce the clinical benefit reported by requiring each participant to knowingly attempt to trigger an IBS attack by ingesting the foods or substances multiple times that they believed caused their symptoms while using the blinded drugs. The study design was unfortunately too demanding, resulting in a large dropout rate and limiting the statistical findings.

Even in spite of this, 25 patients did choose PEZ compared with 14 for placebo as the effective agent among the 39 who completed the study. By intention to treat analysis, which includes those patients who dropped out, 30/49 (61\%) would have chosen enzymes while 19/49 (39\%) would have selected the placebo, trending towards a definite benefit for enzymes although the $\mathrm{p}$ value did not reach statistical significance $(\mathrm{p}=0.078)$.

On a global symptom score from 0 to 10 , patients reported a $74 \%$ reduction in their perceived postprandial symptoms on the enzymes compared with symptoms before starting the study. The enzymes had been used an average of 6 months by the time of the final interview in 2004. We found a significant improvement in the IBSQOL scores compared with baseline among these long term IBS-D sufferers. Moreover, statistical significance was achieved in each IBS-QOL subcategory.

Although there were significant limitations noted with this pilot study, including a high dropout rate, inability to exclude a first drug effect to account for the number of patients choosing PEZ, difficulty measuring the effectiveness of a drug based on specific symptoms reduction and the potential inability of patients 
to identify their triggers accurately or willingness to consume the most triggering agent, it did demonstrate that there was a trend towards significant reduction of IBS-D symptoms with pancreatic enzymes.

The food triggers identified by the patients and the rapidity of the postmeal syndrome suggest a possible relative disaccharidase deficiency. Scientific evidence has demonstrated that the disaccharidase enzymes can be downregulated by medications and food substances. Quercetin, which is found in multiple foods, including onions, is five times more potent than the $\alpha$-glucosidase inhibitor, acarbose. ${ }^{49} 50$ (Onions were identified by $43 \%$ of the participants as a trigger for the postprandial diarrhoea syndrome.) Research has been extensive on locating $\alpha$-glucosidase inhibitors to treat diabetes which have included Vietnamese edible plants ${ }^{51}$ and chamomile tea, ${ }^{52}$ to name only a few items. Therefore, it is possible that the actual food substance that a person is ingesting might result in a transient inhibition of the disaccharidases resulting in the digestive disorder associated with that meal or patients have a relative disaccharidase deficiency. Since $\alpha$-amylase has been shown to potentiate the action of disaccharidases, ${ }^{34}$ 35 the amylase component or other enzymes in PEZ may be ameliorating this effect when taken before the ingestion of the triggering substance.

Further studies are needed to study the effectiveness of PEZ compared with placebo in patients with this condition. In the meantime, however, because PEZ are relatively safe, patients might be offered them as a therapeutic option if their symptoms occur predominately after meals.

Acknowledgements The authors thank Raymond Morgan, PhD, for editing support; WH Money, PhD, for preliminary statistical analysis; Community Foundation of Washington County, MD, for research effort support; and David Whitcomb, MD, PhD.

Funding Pancreatic enzymes were supplied at no cost by Axcan Pharma. The company also funded the statistical analysis and initial editing but was not involved in the planning or conduct of the trial. Small unrestricted grants were received from the Medical Staff of the Washington County Hospital, the Washington County Health Systems Community Health Council Fund and the Hagerstown Medical Laboratory. Individual donations were also received from G Manger, MD, M Elliott, J Hershey and J Morgan.

Competing interests MEM-Axcan Pharma study support only: Viokase medication; funding for statistical analysis and editing of the paper. NT-Novartis, Takeda, GlaxoSmithKline, Dynogen, Tioga.

Ethical approval This randomised controlled trial was approved by the Washington County Hospital Institutional Review Board on 18 January 2002.
Provenance and peer review Not

commissioned; externally peer reviewed.

\section{References}

1. Friedman G. Diet and the irritable bowel syndrome. Gastroenterol Clin North Am 1991;20:313-24.

2. Gertner D, Powell-Tuck J. Irritable bowel syndrome and food intolerance. Practitioner 1994;238:499-502, 504.

3. Cerrato PL. A dietary remedy for irritable bowel syndrome. $R N$ 1987;50:65-6.

4. Nanda R, James R, Smith H, et al. Food intolerance and the irritable bowel syndrome. Gut 1989;30:1099-104.

5. Simrén M, Månsson A, Langkilde AM, et al. Food-related gastrointestinal symptoms in the irritable bowel syndrome. Digestion 2001;63:108-15.

6. Hungin AP, Chang L, Locke GR, et al. Irritable bowel syndrome in the United States: prevalence, symptom patterns and impact. Aliment Pharmacol Ther 2005;21:1365-75.

7. Tillisch K, Chang L. Diagnosis and treatment of irritable bowel syndrome: state of the art. Curr Gastroenterol Rep 2005;7:249-56.

8. Camilleri M, Heading RC, Thompson WG. Clinical perspectives, mechanisms, diagnosis and management of irritable bowel syndrome. Aliment Pharmacol Ther 2002;16:1407-30.

9. Alpers DH. Diet and irritable bowel syndrome. Curr Opin Gastroenterol 2006;22:136-9.

10. Floch MH, Narayan R. Diet in the irritable bowel syndrome. J Clin Gastroenterol 2002;35(1 Suppl):S45-52.

11. Zar S, Kumar D, Benson MJ. Food hypersensitivity and irritable bowel syndrome. Aliment Pharmacol Ther 2001;15:439-49.

12. Shepherd SJ, Parker FC, Muir JG, et al. Dietary triggers of abdominal symptoms in patients with irritable bowel syndrome: randomized placebo-controlled evidence. Clin Gastroenterol Hepatol 2008;6:765-71.

12a. Karnsakul W, Luginbuehl U, Hahn D, et al. Disaccharidase activities in dyspeptic children: biochemical and molecular investigations of maltase-glucoamylase activity. J Pediatr Gastroenterol Nutr 2002;35:551-6.

13. Herber R. Disaccharidase deficiency in health and disease. Calif Med 1972;116:23-37.

14. Bayless TM, Christopher NL. Disaccharidase deficiency. Am J Clin Nutr 1969;22:181-90.

15. Gudmand-Høyer E. The clinical significance of disaccharide maldigestion. Am J Clin Nutr 1994; 59(3 Suppl):735-41S.

16. Talley NJ. Evaluation of drug treatment in irritable bowel syndrome. Br J Clin Pharmacol 2003;56:362-9.

17. Farthing MJ. Treatment options in irritable bowel syndrome. Best Pract Res Clin Gastroenterol 2004;18:773-86.

18. Mearin F. Pharmacological treatment of the irritable bowel syndrome and other functional bowel disorders. Digestion 2006;73(Suppl 1):28-37.

19. Chang HY, Kelly EC, Lembo AJ. Current gut-directed therapies for irritable bowel syndrome. Curr Treat Options Gastroenterol 2006;9:314-23.

20. Bensoussan A. Establishing evidence for Chinese medicine: a case example of irritable bowel syndrome. Zhonghua Yi Xue Za Zhi (Taipei) 2001;64:487-92.

21. Bensoussan A, Talley NJ, Hing M, et al. Treatment of irritable bowel syndrome with Chinese herbal medicine: a randomized controlled trial. JAMA 1998;280:1585-9. 
22. Stefanini GF, Saggioro A, Alvisi V, et al. Oral cromolyn sodium in comparison with elimination diet in the irritable bowel syndrome, diarrheic type. Multicenter study of 428 patients. Scand J Gastroenterol 1995;30:535-41.

23. Stefanini GF, Prati E, Albini MC, et al. Oral disodium cromoglycate treatment on irritable bowel syndrome: an open study on 101 subjects with diarrheic type. Am J Gastroenterol 1992;87:55-7.

24. Thompson WG. The treatment of irritable bowel syndrome. Aliment Pharmacol Ther 2002;16:1395-406.

25. Blanchard EB, Scharff L. Psychosocial aspects of assessment and treatment of irritable bowel syndrome in adults and recurrent abdominal pain in children. J Consult Clin Psychol 2002;70:725-38.

26. Stern RC, Eisenberg JD, Wagener JS, et al. A comparison of the efficacy and tolerance of pancrelipase and placebo in the treatment of steatorrhea in cystic fibrosis patients with clinical exocrine pancreatic insufficiency. Am J Gastroenterol 2000;95:1932-8.

27. Weber AM, Roy CC, Chartrand L, et al. Relationship between bile acid malabsorption and pancreatic insufficiency in cystic fibrosis. Gut 1976;17:295-9.

28. Boyle BJ, Long WB, Balistreri WF, et al. Effect of cimetidine and pancreatic enzymes on serum and fecal bile acids and fat absorption in cystic fibrosis. Gastroenterology 1980;78:950-3.

29. Dutta SK, Anand K, Gadacz TR. Bile salt malabsorption in pancreatic insufficiency secondary to alcoholic pancreatitis. Gastroenterology 1986;91:1243-9.

30. Carroccio A, Guarino A, Zuin G, et al. Efficacy of oral pancreatic enzyme therapy for the treatment of fat malabsorption in HIV-infected patients. Aliment Pharmacol Ther 2001;15:1619-25.

31. Suarez F, Levitt MD, Adshead J, et al. Pancreatic supplements reduce symptomatic response of healthy subjects to a high fat meal. Dig Dis Sci 1999;44:1317-21.

32. Money ME, Hofmann AF, Hagey LR, et al. Treatment of irritable bowel syndrome-diarrhea with pancrealipase or colesevelam and association with steatorrhea. Pancreas 2009;38:232-3.

33. Leeds JS, Hopper AD, Sidhu R, et al. Some patients with irritable bowel syndrome may have exocrine pancreatic insufficiency. Clin Gastroenterol Hepatol 2010;8:433-8.

34. Nichols BL, Quezada-Calvillo R, Robayo-Torres CC, et al. Mucosal maltase-glucoamylase plays a crucial role in starch digestion and prandial glucose homeostasis of mice. J Nutr 2009;139:684-90.

35. Quezada-Calvillo R, Robayo-Torres CC, Opekun AR, et al. Contribution of mucosal maltase-glucoamylase activities to mouse small intestinal starch alpha-glucogenesis. J Nutr 2007;137:1725-33.

36. Thompson WG, Longstreth GF, Drossman DA, et al. Functional bowel disorders and functional abdominal pain. Gut 1999;45(Suppl 2):II43-7.
37. Lembo TJ, Fink RN. Clinical assessment of irritable bowel syndrome. J Clin Gastroenterol 2002;35(1 Suppl):S31-6.

38. Patrick DL, Drossman DA, Frederick IO, et al. Quality of life in persons with irritable bowel syndrome: development and validation of a new measure. Dig Dis Sci 1998;43: 400-11.

39. Schlumberger W, Olbrich S, Muller-Kunert E, et al. Antikorper gegen Gliadin und gegen Endomusium zur Diagnose der Gluten-sensitiven Enteropathie. J Lab Med 1993;17:246.

40. Chorzelski TP, Beutner EH, Sulej J, et al. IgA antiendomysium antibody. A new immunological marker of dermatitis herpetiformis and coeliac disease. Br J Dermatol 1984;111:395-402.

41. Imamura S, Hirayama T, Arai T, et al. An enzymatic method using 1,2 diglyceride for pancreatic lipase in serum. Clin Chem 1989;35:1126.

42. Scheefers-Borchel U, Scheefers H, Arnold R, et al. Pankreatische Elastase-1: Parameter fur die chronische und akute pankreatitis. Lab Med 1992;16:427-74.

43. Hammer J, Talley NJ. Diagnostic criteria for the irritable bowel syndrome. Am J Med 1999;107:5S-11S.

44. Jellema P, van der Windt DA, Schellevis FG, et al. Systematic review: accuracy of symptom-based criteria for diagnosis of irritable bowel syndrome in primary care. Aliment Pharmacol Ther 2009;30:695-706.

45. Camilleri M, McKinzie S, Busciglio I, et al. Prospective study of motor, sensory, psychologic, and autonomic functions in patients with irritable bowel syndrome. Clin Gastroenterol Hepatol 2008;6:772-81.

46. Manabe N, Wong BS, Camilleri M, et al. Lower functional gastrointestinal disorders: evidence of abnormal colonic transit in a 287 patient cohort. Neurogastroenterol Motil 2010;22:293-e82.

47. Deiteren A, Camilleri M, Burton D, et al. Effect of meal ingestion on ileocolonic and colonic transit in health and irritable bowel syndrome. Dig Dis Sci 2010;55:384-91.

48. Camilleri M. Do the symptom-based, Rome criteria of irritable bowel syndrome lead to better diagnosis and treatment outcomes? The con argument. Clin Gastroenterol Hepatol 2010;8:129.

49. Slimestad R, Fossen T, Vågen IM. Onions: a source of unique dietary flavonoids. J Agric Food Chem 2007;55:10067-80.

50. Li YQ, Zhou FC, Gao F, et al. Comparative evaluation of quercetin, isoquercetin and rutin as inhibitors of alphaglucosidase. J Agric Food Chem 2009;57:11463-8.

51. Mai TT, Thu NN, Tien PG, et al. Alpha-glucosidase inhibitory and antioxidant activities of Vietnamese edible plants and their relationships with polyphenol contents. J Nutr Sci Vitaminol 2007;53:267-76.

52. Kato A, Minoshima Y, Yamamoto J, et al. Protective effects of dietary chamomile tea on diabetic complications. J Agric Food Chem 2008;56:8206-11. 